\title{
The characteristics and related factors of insomnia among postoperative patients with gastric cancer: a cross-sectional survey
}

\author{
Guang-hui Zhu ${ }^{1,2} \cdot$ Juan $\mathrm{Li}^{1,2} \cdot$ Jie Li $^{1} \cdot$ Bo-wen $\mathrm{Xu}^{1,2} \cdot$ He-ping Wang ${ }^{1} \cdot$ Xin-miao Wang ${ }^{1} \cdot$ Jia-qi Hu ${ }^{1,2} \cdot$ Ming-hao Dai $^{3}$
}

Received: 16 January 2021 / Accepted: 14 May 2021 / Published online: 27 May 2021

(C) The Author(s) 2021

\begin{abstract}
Purpose This study aims to explore the characteristics and related factors of insomnia of patients after operation for gastric cancer. Methods A cross-sectional survey was carried out and finally 115 patients with insomnia after operation for gastric cancer were included. The general information, gastric cancer-related information, sleep quality, and other symptoms were investigated.

Results (1) The Pittsburgh sleep quality index score of most insomnia patients after gastric cancer surgery was 11-15 points, and the sleep quality rating was "poor". (2) The sleep quality of patients with insomnia after surgery for gastric cancer is related to the number of chemotherapy cycles, fatigue, and depression. (3) The probability of reduced sleep quality with the number of chemotherapy cycles $>6$ is 3.640 times that of $\leq 6$. The probability of reduced sleep quality during moderate to severe fatigue was 4.390 times that of patients with no or mild fatigue.

Conclusion Attention to related factors may be associated with improvement of sleep quality in patients with gastric cancer after surgery.
\end{abstract}

Keywords Gastric cancer $\cdot$ Insomnia $\cdot$ Postoperative $\cdot$ Characteristics $\cdot$ Related factors

\section{Introduction}

According to the World Health Organization (WHO), there were 896.63 million cancer deaths worldwide in 2016, making it the second leading cause of death [1]. Based on GLOBOCAN 2018 statistics, the incidence and death of gastric cancer accounted for the 5th and 3rd of all malignant tumors all over the world, respectively [2]. Anti-tumor tends to be comprehensive measures [3-5]. With the continuous

Juan Li contributed equally with Guang-hui Zhu, and is the co-first author of this article.

Jie Li

qfm2020jieli@yeah.net

1 Guang'anmen Hospital, China Academy of Chinese Medical Sciences, No. 5, Beixian Ge Street, Xicheng District, Beijing 100053 , China

2 Graduate School, Beijing University of Chinese Medicine, No. 11, Beisanhuan Dong Road, Chaoyang District, Beijing 100029, China

3 Peking University Health Science Center, No. 38, Xueyuan Road, Haidian District, Beijing 100191, China improvement of treatment, the survival period of cancer patients has been prolonged. Improving the quality of life of cancer patients has gradually become the focus of attention and urgent problems to be solved for patients, families, society, and clinicians. Symptom management of tumor patients has gradually become a hot spot for medical personnel and scientific researchers $[6,7]$.

Insomnia can lead to adverse health problems. In addition to the potential for physical, psychological, and social problems, they are more likely to contribute to the development of diseases, including cardiovascular disease and cancer [8]. Patients with insomnia have a moderate risk of developing cancer [8-11]. Studies have shown that insomnia damages DNA and reduces the body's ability to repair it, possibly increasing the risk of cancer [12]. In addition, short sleep duration has been linked to cancer mortality [13]. The incidence of insomnia in patients with malignant tumors is 52.6-67.4\%, which is twice that of the general population $[14,15]$. However, if effective intervention is not given, chronic insomnia often develops [16, 17]. It will increase the psychological burden of cancer patients, reduce the effect of anti-tumor treatment, and seriously affect the health of patients [18, 19]. Researches, in recent years, have found that insomnia became 
a common clinical symptom in cancer patients, but patients and doctors did not pay enough attention and treatment to insomnia [17, 20]. Early intervention may reduce the severity or longevity of these problems during treatment [21].

In 1986, Spielman et al. have introduced the behavioral perspective on insomnia (the "3P" model), and conceptualized the influencing factors of insomnia into three categories: predisposing factors for insomnia, precipitating factors for insomnia attacks, and perpetuating factors for maintaining long-term insomnia [22]. At present, the "3P" model is still a popular model for the pathogenesis of chronic insomnia [23]. This model believes that individual susceptibility and innate tendency (such as high arousal or anxiety), and encounter predisposing factors (such as stressful events or diseases), will lead to acute insomnia. However, negative thoughts and non-adaptive coping behaviors (such as excessive concern and worry about insomnia) will produce conditioned arousal, and chronic insomnia will occur after repeated [24]. Most studies have included small sample sizes of participants with different characteristics, which may make it impossible to conduct subgroup analysis and identify potential related factors for insomnia [25]. Although a number of factors have been linked to the development of insomnia in cancer patients (e.g., gender, age, cancer treatment), the results have been mixed when it comes to related factors [26]. Surgical resection is the preferred treatment for gastric cancer [27]. Wang X. et al. found that the incidence of disturbed sleep was $90.48 \%$ and the risk of symptoms was about 4 points through investigation and analysis of the symptoms of patients after gastric cancer [28]. However, no studies have explored the characteristics and influencing factors of insomnia in postoperative patients with gastric cancer.

Recent studies have shown that insomnia is linked to other symptoms. The simultaneous occurrence of at least two symptoms can be classified into clusters of symptoms that are clinically significant and interrelated [29, 30]. Different clusters of sleeprelated symptoms, including fatigue and depression, have been reported in cancer patients [31-33]. However, due to the limitations of previous studies, the association between insomnia and other symptoms has not been fully studied, including the lack of effective questionnaires to measure insomnia [31-35].

Based on the " $3 \mathrm{P}$ " model of insomnia, we started this study in order to understand the characteristics of postoperative insomnia in patients with gastric cancer, find out the possible related factors for insomnia, and explore the interaction between insomnia and other symptoms.

\section{Methods}

\section{Participants}

The cross-sectional study included patients who attended the Oncology Clinic of Guang'anmen Hospital, China Academy of Chinese Medical Sciences between April 2019 and January 2020. The diagnosis of gastric cancer refers to "Regulations for Diagnosis and Treatment of Gastric Cancer (2018 Edition)" [3] and "American Joint Committee on Cancer (AJCC) gastric cancer TNM staging (the 8th version)" [36]. Insomnia is diagnosed on the "Chinese Classification and Diagnostic Criteria for Mental Disorders" (the 3rd version) [37]: (1) difficulty falling asleep, (2) often awakening and unstable sleep, (3) difficulty falling asleep again after waking up, awakening prematurely in the morning, (4) sleeping less than $6 \mathrm{~h}$, lack of energy during the day, and drowsiness, and (5) history of repeated attacks, occurring $\geq 3$ times a week and lasting $\geq 1$ month.

The cases were screened according to the following: (1) The patients diagnosed with gastric cancer, and the staging being $\mathrm{T}_{1-4} \mathrm{~N}_{\mathrm{X}} \mathrm{M}_{0}$; (2) within 6-8 months after standard radical gastrectomy; (3) meeting the diagnostic criteria for insomnia, and the Pittsburgh sleep quality index (PSQI) score being $>5$ points; (4) no symptoms of insomnia within 1 month before surgery and not taking drugs with sleeping effects (based on clinical records or as reported by patient); (5) over 18 years old; (6) Karnofsky (KPS) score being $\geq 60$ points; (7) having sufficient cognitive ability to complete the survey; and (8) signing the informed consent form voluntarily.

\section{Procedures}

This study was part of a project of Beijing Science and Technology Commission. The proposal was approved by the Ethics Committee of Guang'anmen Hospital, China Academy of Chinese Medical Sciences (NO. 2016-118KY-02). Potential participants were approached and invited to the study on the first day they were admitted to the hospital. This was a convenience sample. The method and purpose of the research were explained to them. After the patients signing the informed consent form, the inclusion criteria were determined, and information was collected for patients who met the inclusion criteria.

\section{Measurements}

(1) General information includes age, gender, and KPS score; (2) relevant data of gastric cancer are pathological type, differentiation grade, Lauren grade, clinical staging, TNM staging, lesion location, surgical method, and number of chemotherapy cycles; (3) main observation index is PSQI scale score; (4) other observation indicators are Piper Fatigue Scale-Chinese Version (PFS-CV) score, and Hospital Anxiety and Depression Scale (HADS) score. 
PSQI

The PSQI scale is used to evaluate sleep quality. It consists of self-evaluation and other-evaluated items, and only 19 self-evaluation items participated in the scoring, including 7 components [38]. Every component is scored on a scale of $0-3$, and the total score ranges from 0 to 21. $\mathrm{PSQI}$ score $=$ component $(\mathrm{A}+\mathrm{B}+\mathrm{C}+\mathrm{D}+\mathrm{E}+\mathrm{F}+$ $\mathrm{G})$. Table 1 presents the correlation between total PSQI score and sleep quality. The score is higher, the worse the quality of sleep. The diagnostic sensitivity of this scale is $89.6 \%$, and the specificity is $86.5 \%$ (kappa $=$ $0.75, \mathrm{P} \leq 0.001)[21]$.

\section{PFS-CV}

The PFS-CV was translated by scholars from Hong Kong in 2003, including 4 dimensions of behavior, emotion, feeling, and cognition, with a total of 22 contents. The repeat test reliability is 0.98 [39]. Every content contains 11 points (010 points). Patients are scored according to the degree of their fatigue. Among them, there are 5 items for evaluating feelings and emotions, and 6 items for evaluating cognition and behaviors. The final score is derived from the average score of 4 dimensions. The score is higher, the heavier the fatigue; 0 means asymptomatic, 1-3 means mild, 4-6 means moderate, and 7-10 means severe.

\section{HADS}

In 1983, Zigmond AS. et al. designed HADS [40]. After tested, the anxiety subscale (A), depression subscale (D), and HADS total score have good retest consistency [41]. There are a total of 14 questions in the table. Among them, the seven questions of A test are used to evaluate anxiety, and the seven questions of $\mathrm{D}$ test are used to evaluate depression. Every question is counted as $0-3$ points according to the degree level. The score is higher, the more severe the degree; $0-7$ is asymptomatic, $8-10$ is suspicious, and $11-21$ is symptomatic. It is divided into 8 boundaries, $<8$ is negative, and $\geq 8$ is positive.

Table 1 The correlation between total PSQI score and sleep quality

\begin{tabular}{ll}
\hline The total score of PSQI & Sleep quality \\
\hline $0-5$ & Good \\
$6-10$ & General \\
$11-15$ & Poor \\
$16-21$ & Very poor \\
\hline
\end{tabular}

\section{Data analysis}

(1) Statistical description method includes mean \pm standard deviation $(-\mathrm{x} \pm \mathrm{S})$, composition ratio, and median and quartile [M (Q25, Q75)].

(2) Statistical inference method: When the data conforms to the normal distribution and the variance is uniform, the independent sample $t$ test is used to compare the samples between groups. When the variance is not uniform, the independent sample approximate $t$ test is used. Non-normally distributed samples between groups use non-parametric test (MannWhitney U test). One-way ANOVA test or Kruskal-Wallis test was used for sample comparison among multiple groups. Multivariate binary unconditional logistic regression analysis is used to analyze categorical variables. Pearson correlation coefficient is used for correlation analysis of numerical variables.

The SPSS 24.0 software was used for statistical analysis of all data, using a two-sided difference test. $\mathrm{P} \leq 0.05$ is considered statistically significant.

\section{Results}

A total of 141 cases of postoperative patients with gastric cancer were initially screened, and 115 cases were finally included. According to the rough estimation method of sample size, the sample size is $5-10$ times the number of variables [42]. The number of variables in this study is 15 , requiring a sample size of 75-150 cases, so the number of cases included in this study met the requirements. Figure 1 presents the process of recruiting study participants. General data, gastric cancer data, and other symptom data of the included cases were presented in Table 2.

\section{The characteristics}

There were 60 cases $(52.17 \%)$ with a PSQI score of $11-15,37$ cases $(32.17 \%)$ with a score of $7-10$, and 18 cases $(15.65 \%)$ with a score of 16-21. The average score of the PSQI score was $12.05 \pm 3.25$. Among them, the "daytime dysfunction" component had the highest score, and the hypnotic drug component had the lowest score (see Table 3).

\section{Related factors}

\section{General information}

The independent sample $t$ test was used to compare the PSQI scores of gender and age groups, $\mathrm{t}=-0.010$ and $-1.092, P$ all $>0.05$. The PSQI score of KPS group was subjected to nonparametric test (Mann-Whitney $\mathrm{U}$ test), $\mathrm{Z}=-0.010, P>0.05$; Table 4. 


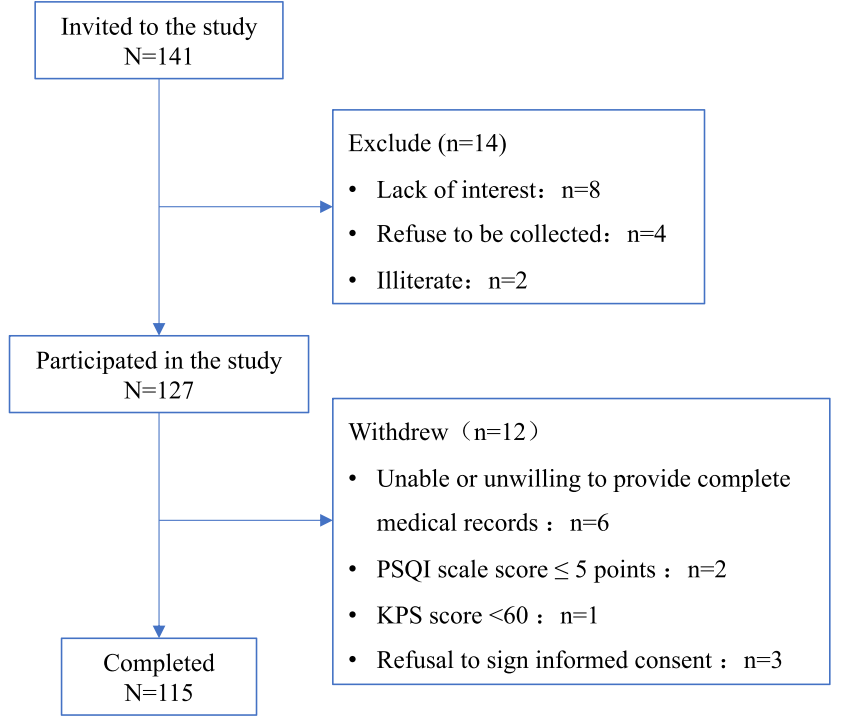

Fig. 1 Flowchart of the study recruitment

\section{Relevant data of gastric cancer}

Kruskal-Wallis tests were respectively performed on the PSQI scores among the groups of the lesion site, differentiation grade, Lauren type, clinical stage, $\mathrm{N}$ stage, and surgical method, $\chi^{2}=3.111,4.664,2.350,1.576,0.715$, and 5.292, $P$ all $>0.05$. One-way ANOVA test was used in the PSQI scores among the group of the $\mathrm{T}$ stage, $\mathrm{F}=0.793, P>$ 0.05 ; Table 5 .

The PSQI scores of the number of chemotherapy cycles grouped ( $\leq 6$ cycles, $>6$ cycles) were subjected to nonparametric test (Mann-Whitney $\mathrm{U}$ test), $\mathrm{Z}=-4.447, P=$ 0.000; Supplementary Table 1.

\section{Fatigue, depression, and anxiety}

The Pearson correlation coefficients between the total PSQI score and the final score of the PFS-CV scale, between the total PSQI score and the HADS scale (depression subscale) score, and between the total PSQI score and the HADS scale (anxiety subscale) score were respectively $0.428,0.261$, and 0.060 . $P=0.000,0.005$, and 0.527; Supplementary Figure 1, Supplementary Figure 2, and Supplementary Figure 3.

\section{Related factors}

The PSQI score was used as the dependent variable and assigned a value: $0=$ "PSQI score $<11$ points (sleep quality is general)" and $1=$ "PSQI score $\geq 11$ points" (sleep quality is poor or very poor). The above related factors with $P<0.05$ (the number of cycles of chemotherapy, the PFS-CV scale, the HADS scale (depression subscale)) were used as independent variables and assigned values: $0=$ "the number of chemotherapy cycles $\leq 6, " 1=$ "the number of chemotherapy
Table 2 Basic information of included cases $(n=115)$

\begin{tabular}{|c|c|c|}
\hline Group & Number & Percent \\
\hline \multicolumn{3}{|l|}{ Gender group } \\
\hline Male & 73 & $63.48 \%$ \\
\hline Female & 42 & $36.52 \%$ \\
\hline \multicolumn{3}{|l|}{ Age group } \\
\hline$\leq 60$ & 63 & $53.78 \%$ \\
\hline$>60$ & 52 & $46.22 \%$ \\
\hline \multicolumn{3}{|l|}{ KPS group } \\
\hline$<90$ & 35 & $30.43 \%$ \\
\hline$\geq 90$ & 80 & $69.57 \%$ \\
\hline \multicolumn{3}{|l|}{ Lesion site } \\
\hline Gastric cardia & 22 & $21.36 \%$ \\
\hline The body of the stomach & 38 & $36.89 \%$ \\
\hline The antrum of the stomach & 43 & $41.75 \%$ \\
\hline \multicolumn{3}{|l|}{ Degree of differentiation } \\
\hline High differentiation & 4 & $3.81 \%$ \\
\hline Poor differentiation & 60 & $57.14 \%$ \\
\hline Moderate differentiation & 28 & $26.67 \%$ \\
\hline Moderate to poor differentiation & 13 & $12.38 \%$ \\
\hline \multicolumn{3}{|l|}{ Lauren type } \\
\hline Intestinal type & 26 & $28.89 \%$ \\
\hline Diffuse type (stomach type) & 44 & $48.89 \%$ \\
\hline Hybrid & 20 & $22.22 \%$ \\
\hline \multicolumn{3}{|l|}{ Clinical stage } \\
\hline I & 6 & $5.22 \%$ \\
\hline II & 41 & $35.65 \%$ \\
\hline III & 68 & $59.13 \%$ \\
\hline \multicolumn{3}{|l|}{ T stage } \\
\hline $\mathrm{T} 1$ & 7 & $6.09 \%$ \\
\hline $\mathrm{T} 2$ & 26 & $22.61 \%$ \\
\hline $\mathrm{T} 3$ & 48 & $41.74 \%$ \\
\hline $\mathrm{T} 4$ & 34 & $29.56 \%$ \\
\hline \multicolumn{3}{|l|}{$\mathrm{N}$ stage } \\
\hline No & 24 & $20.87 \%$ \\
\hline N1 & 34 & $29.57 \%$ \\
\hline N2 & 25 & $21.74 \%$ \\
\hline $\mathrm{N} 3$ & 32 & $27.83 \%$ \\
\hline \multicolumn{3}{|l|}{ Surgical methods } \\
\hline Proximal gastrectomy & 19 & $16.52 \%$ \\
\hline Distal gastrectomy & 38 & $33.04 \%$ \\
\hline Total gastrectomy & 58 & $50.43 \%$ \\
\hline \multicolumn{3}{|l|}{ The number of chemotherapy cycle } \\
\hline$\leq 6$ & 55 & $52.88 \%$ \\
\hline$>6$ & 49 & $47.12 \%$ \\
\hline \multicolumn{3}{|l|}{ PSQI score } \\
\hline $7-10$ & 37 & $32.17 \%$ \\
\hline $11-15$ & 60 & $52.17 \%$ \\
\hline $16-21$ & 18 & $15.65 \%$ \\
\hline \multicolumn{3}{|l|}{ PFS-CV score } \\
\hline$\leq 4$ & 43 & $37.39 \%$ \\
\hline$>4$ & 72 & $62.61 \%$ \\
\hline \multicolumn{3}{|l|}{ HADS score } \\
\hline \multicolumn{3}{|l|}{ Anxiety subtable } \\
\hline$<8$ & 17 & $14.78 \%$ \\
\hline$\geq 8$ & 98 & $85.22 \%$ \\
\hline \multicolumn{3}{|l|}{ Depression subtable } \\
\hline$<8$ & 28 & $24.35 \%$ \\
\hline$\geq 8$ & 87 & $75.65 \%$ \\
\hline
\end{tabular}

cycles $>6$ "; $0=$ "PFS-CV scale $\leq 4$ points," 1 = "PFS-CV scale $>4$ points"; and $0=$ "HADS scale (depression subscale) $<8$ points," 1 = "HADS scale (depression subscale) $\geq 8$ points". A 
Table 3 PSQI scale components and scores

\begin{tabular}{ll}
\hline & Score $(-\mathrm{x} \pm \mathrm{S})$ \\
\hline A. Sleep quality & $2.09 \pm 0.78$ \\
B. Time to fall asleep & $2.04 \pm 0.73$ \\
C. Sleep time & $1.90 \pm 0.82$ \\
D. Sleep efficiency & $1.68 \pm 1.01$ \\
E. Sleep disorders & $1.45 \pm 0.63$ \\
F. Hypnotic drugs & $0.63 \pm 1.12$ \\
G. Daytime dysfunction & $2.17 \pm 0.85$ \\
Total score & $11.96 \pm 3.31$ \\
\hline
\end{tabular}

multivariate binary unconditional logistic regression model was established, and the forward method was used to select and eliminate independent variables. The regression analysis showed that the number of chemotherapy cycles and fatigue was significant related factors for the reduction of sleep quality in patients with insomnia $(P<0.05)$.

Compared with the number of chemotherapy cycles $\leq 6$, when the number of previous chemotherapy cycles after gastric cancer surgery is greater than 6 , the risk of reduced sleep quality is increased (OR $=3.640,95 \%$ CI: $1.416-9.357, P=$ 0.007). Compared with patients with no or mild fatigue, patients with moderate or severe fatigue after gastric cancer surgery have an increased risk of sleep quality $(\mathrm{OR}=4.390,95 \%$ CI:1.843-10.460, $P=0.001$; Supplementary Table 2).

\section{Discussion}

This study investigated the characteristics of sleep quality included in patients. It was found that poor sleep quality accounted for $52.17 \%$; patients with very poor sleep quality accounted for $15.65 \%$. In the analysis of related factors, the total PSQI score was not statistically different among the groups of gender, age, KPS score, gastric cancer lesion location, differentiation grade, Lauren classification, clinical stage, $\mathrm{T}$ stage, and $\mathrm{N}$ stage $(P>0.05)$. That showed that the severity

Table 4 Correlation analysis of general data and PSQI score

\begin{tabular}{|c|c|c|c|c|c|}
\hline & & $\mathrm{n}$ & $\begin{array}{l}\text { PSQI score } \\
\left(\begin{array}{c}x \pm S)\end{array}\right.\end{array}$ & $\mathrm{t}$ & $P$ \\
\hline \multirow[t]{2}{*}{ Gender } & Male & 73 & $11.96 \pm 3.08$ & \multirow[t]{2}{*}{-0.010} & \multirow[t]{2}{*}{0.992} \\
\hline & Female & 42 & $11.95 \pm 3.71$ & & \\
\hline \multirow[t]{3}{*}{ Age } & $\leq 60$ & 63 & $11.65 \pm 3.66$ & \multirow[t]{2}{*}{-1.092} & \multirow[t]{2}{*}{0.277} \\
\hline & $>60$ & 52 & $12.33 \pm 2.81$ & & \\
\hline & & & M (Q25, Q75) & Z & $P$ \\
\hline \multirow[t]{2}{*}{ KPS } & $<90$ & 18 & $12.00(12.00,14.00)$ & \multirow[t]{2}{*}{-1.706} & \multirow[t]{2}{*}{0.088} \\
\hline & $\geq 90$ & 40 & $11.00(8.25,14.00)$ & & \\
\hline
\end{tabular}

$\Delta P>0.05$ of insomnia in patients after gastric cancer surgery was not significantly related to the above factors. At present, some studies have concluded that gender, age, cancer stage, and other factors have nothing to do with the degree of insomnia in the included cases, which was the same as the results of this study $[20,21,43]$. However, there were still studies that differ from the results of this study. Ohayon MM et al. believed that gender and age were factors that induce insomnia in cancer patients [44]. We will need to design a prospective study including a larger sample size to verify the conclusions.

By analyzing the influence of the number of chemotherapy cycles on the degree of insomnia, it was found that the total PSQI score of patients with chemotherapy cycles $>6[13$ (12, 16)] was significantly higher than that of patients with chemotherapy cycles $\leq 6[10(8,12)](P=0.000)$. The multivariate binary unconditional logistic regression analysis showed that the number of chemotherapy cycles $>6$ was a significant related factor for reduced sleep quality in patients with insomnia after operation for gastric cancer $(P<0.05)$. The risk of reduced sleep quality with the number of chemotherapy cycles $>6$ is 3.640 times that of $\leq 6$. Chemotherapy, as one of the main anti-tumor treatments, has a certain cytotoxic effect, causing patients to have side effects such as anorexia, nausea, vomiting, fatigue, pain, and bone marrow suppression. As a result, the patient loses confidence in the treatment effect, and insomnia also occurs or worsens $[45,46]$. The result of a cross-sectional study looking at new-onset insomnia in cancer patients during chemotherapy showed that $42.8 \%$ of the 213 patients surveyed reported insomnia, and $31.9 \%$ of them reported severe insomnia [6]. In addition, the cerebral toxicity caused by the use of chemotherapeutic drugs contributes to the progression of brain inflammation by affecting the production and distribution of pro-inflammatory cytokines [47]. With the prolonged use of chemotherapeutic drugs, the tendency of insomnia in patients was aggravated. An 18-month study found that insomnia in cancer patients receiving chemotherapy increased with the length of time they took the drug [48].

The sleep quality of insomnia patients after gastric cancer surgery was positively correlated with fatigue and depression (Pearson $=0.428$ and $0.261, P=0.000$ and 0.005 ), but not correlated with anxiety $(P=0.527)$. Hoang HTX et al. also found that the incidence and severity of insomnia in cancer patients had nothing to do with the characteristics of the participants, cancer information, or treatment factors, but were related to the emotional score of the participants [6]. The results of a systematic review also pointed out that patients with insomnia and mood have a two-way effect [49]. The hypothalamus, hippocampus, and other brain tissues regulate emotion and sleep at the same time by secreting neuropeptides and neurotransmitters, so that the two are connected [50, 51]. A Chinese study also found that when a patient suffered from depression and insomnia, the level of neuropeptide $\mathrm{Y}$ in the body was lower than that of healthy people, and the level of 
Table 5 Correlation analysis between gastric cancer data and PSQI score

\begin{tabular}{|c|c|c|c|c|c|}
\hline & & $\mathrm{n}$ & PSQI score & $x^{2}$ & $P$ \\
\hline \multirow{3}{*}{ Lesion site } & Gastric cardia & 22 & & \multirow{3}{*}{3.111} & \multirow{3}{*}{$0.211^{\wedge}$} \\
\hline & Body of the stomach & 38 & $12.5(8,16)$ & & \\
\hline & Antrum of the stomach & 43 & $12(11,14)$ & & \\
\hline \multirow[t]{4}{*}{ Differentiation grade } & High differentiation & 4 & $12(12,12)$ & \multirow[t]{4}{*}{4.664} & \multirow[t]{4}{*}{$0.198^{\wedge}$} \\
\hline & Poor differentiation & 60 & $11(9,13.75)$ & & \\
\hline & Moderate differentiation & 28 & $13.5(8,16)$ & & \\
\hline & Moderate to poor differentiation & 13 & $11(8,12.5)$ & & \\
\hline \multirow[t]{3}{*}{ Lauren type } & Intestinal type & 26 & $12(9.75,16.25)$ & \multirow[t]{3}{*}{2.350} & \multirow[t]{3}{*}{$0.309^{\wedge}$} \\
\hline & Diffuse type (stomach type) & 44 & $12(10,14)$ & & \\
\hline & Hybrid & 20 & $11(8,13)$ & & \\
\hline \multirow[t]{3}{*}{ Clinical stage } & I & 6 & $13(11,16)$ & \multirow[t]{3}{*}{1.576} & \multirow[t]{3}{*}{$0.455^{\boldsymbol{\Lambda}}$} \\
\hline & II & 41 & $12(9,13.5)$ & & \\
\hline & III & 68 & $12(10,14)$ & & \\
\hline \multirow[t]{4}{*}{ N stage } & $\mathrm{N}_{0}$ & 24 & $12(10.25,15.25)$ & \multirow[t]{4}{*}{0.715} & \multirow[t]{4}{*}{$0.870^{\wedge}$} \\
\hline & $\mathrm{N}_{1}$ & 34 & $12(9,14)$ & & \\
\hline & $\mathrm{N}_{2}$ & 25 & $12(9.5,14)$ & & \\
\hline & $\mathrm{N}_{3}$ & 32 & $12(10,14.75)$ & & \\
\hline \multirow[t]{4}{*}{ Surgical methods } & Proximal gastrectomy & 19 & $11(7,12)$ & \multirow[t]{3}{*}{5.292} & \multirow[t]{3}{*}{0.071} \\
\hline & Distal gastrectomy & 38 & $12(11,14)$ & & \\
\hline & Total gastrectomy & 58 & $12(8.75,14.25)$ & & \\
\hline & & $\mathrm{n}$ & $(-x \pm S)$ & $\mathrm{F}$ & $P$ \\
\hline \multirow[t]{4}{*}{ T stage } & $\mathrm{T}_{1}$ & 4 & $12.25 \pm 0.96$ & \multirow[t]{4}{*}{0.793} & \multirow[t]{4}{*}{$0.503^{\wedge}$} \\
\hline & $\mathrm{T}_{2}$ & 13 & $12.92 \pm 3.82$ & & \\
\hline & $\mathrm{T}_{3}$ & 24 & $12.21 \pm 3.40$ & & \\
\hline & $\mathrm{T}_{4}$ & 17 & $11.12 \pm 2.89$ & & \\
\hline
\end{tabular}

${ }^{\wedge}>0.05$ substance P was higher than that of healthy people [52]. In addition, insomnia and fatigue often occur simultaneously in cancer patients. Xu JN's study included 60 patients with cancer-related fatigue and found that $70 \%$ of them suffered from insomnia [53]. Moreover, this study established a multivariate binary unconditional logistic regression analysis to show that the risk of reduced sleep quality in patients with moderate or severe fatigue after gastric cancer surgery was 4.390 times that of patients with no or mild fatigue $(P=$ $0.001)$.

The advantage of this study was to specifically select patients with insomnia after operation for gastric cancer to explore their sleep quality characteristics and related factors.

\section{Study limitations}

However, this study was a cross-sectional study. There is no control group to give the finding perspective or relevance for the findings of prevalence and severity. Due to its inherent limitations, this study cannot point out how insomnia and its related symptoms affect each other before they appear and how they change throughout the course of the disease. In addition, the insomnia of the included patients in this study was judged based on the history collection and the evaluation of the PSQI, but it may be caused by the error of patients' recollection that caused the wrong judgment of insomnia. Thirdly, due to limited research funds and time, this study did not observe other symptoms of patients, such as postoperative pain, sleep apnea, and dyspnea, which is a defect of this study. Finally, this study was only a single-center study, so there was certain selection error.

\section{Clinical implications}

This study confirmed that the sleep quality of insomnia patients after operation for gastric cancer was mainly "poor". That was correlated with the number of chemotherapy cycles, depression, and fatigue. The number of chemotherapy cycles $>6$ and moderate to severe fatigue was the negative correlation factors for reducing sleep quality in insomnia patients after operation for gastric cancer. Conclusions indicated that the quality of sleep in cancer patients might be related to previous treatments. Early assessment of insomnia and immediate intervention will be needed to improve the quality of life of cancer patients and their treatment compliance. Because insomnia may occur in all stages of cancer development and treatment, some patients have insomnia symptoms in the early 
stage of the tumor. In the course of treatment, early interventions may reduce the severity or longevity of these problems, such as exercise therapy, psychotherapy, or medication, to prevent the insomnia from worsening with anti-tumor therapy $[21,54]$. Cancer patients may have symptom clusters including insomnia, depression, and fatigue, and they may affect each other. Therefore, further research can be carried out to explore the incidence and characteristics of insomnia in cancer patients at different treatment stages.

\section{Conclusion}

Attention to related factors may be associated with improvement of sleep quality in patients with gastric cancer after surgery.

Supplementary Information The online version contains supplementary material available at https://doi.org/10.1007/s00520-021-06295-6.

Code availability Not applicable.

Author contribution GZ and Juan L contributed equally to this work. Jie L was involved in study concept and design. GZ and Juan L wrote the first draft. Jie L, BX, MD, HW, XW, and JH contributed to the revision of the final report. All authors read and approved the final manuscript.

Funding This work was supported by grants from the Beijing Science and Technology Project (No. D161100005116004).

Data Availability Not applicable.

\section{Declarations}

Ethical approval The study obtained ethical approval from the Ethics Committee of Guang'anmen Hospital, China Academy of Chinese Medical Sciences.

Consent to participate Informed consent was obtained from all individual participants included in the study.

Consent for publication Written informed consent for publication was obtained from all participants.

Conflict of interest The authors declare no competing interests.

Open Access This article is licensed under a Creative Commons Attribution 4.0 International License, which permits use, sharing, adaptation, distribution and reproduction in any medium or format, as long as you give appropriate credit to the original author(s) and the source, provide a link to the Creative Commons licence, and indicate if changes were made. The images or other third party material in this article are included in the article's Creative Commons licence, unless indicated otherwise in a credit line to the material. If material is not included in the article's Creative Commons licence and your intended use is not permitted by statutory regulation or exceeds the permitted use, you will need to obtain permission directly from the copyright holder. To view a copy of this licence, visit http://creativecommons.org/licenses/by/4.0/.

\section{References}

1. The World Health Organization (2018) Global health estimates 2016:deaths by cause, age, sex, by country and by region, 20002016[DB/OL]. Geneva: World Health Organization (2018-0415)[2020-06-05]. http://www.who.int/healthinfo/global_burden_ disease/estimates/en/

2. Bray F, Ferlay J, Soerjomataram I, Siegel RL, Torre LA, Jemal A (2018) Global cancer statistics 2018: GLOBOCAN estimates of incidence and mortality worldwide for 36 cancers in 185 countries. CA Cancer J Clin 68(6):394-424

3. National Health Commission (2019) Standards for diagnosis and treatment of gastric cancer (2018 Edition). Chin J Digest Med Imageol (Electron Ed) 9(03):118-144 (in China)

4. Wu J, Zhang D, Ni M, Xue J et al (2020) Effectiveness of Huachansu injection combined with chemotherapy for treatment of gastric cancer in China: a systematic review and Meta-analysis. J Tradit Chin Med 40(5):749-757

5. Peng W, Zhang F, Wang Z, Li D, He Y, Ning Z, Sheng L, Wang J, Xia X, Yu C, Wang Z, Zhao Y, Liang H, Hu B, Sun C, Wang D, Cheng Y, Pan M, Xia L, Guo X, Zhang Y, Hu Z, Li X, Lu L, Zhang J, Qian H, Xie H, Sun G (2020) Large scale, multicenter, prospective study of apatinib in advanced gastric cancer: a real-world study from China. Cancer Manag Res 12:6977-6985

6. Hoang HTX, Molassiotis A, Chan CW, Nguyen TH, Liep Nguyen $\mathrm{V}$ (2020) New-onset insomnia among cancer patients undergoing chemotherapy: prevalence, risk factors, and its correlation with other symptoms. Sleep Breath 24(1):241-251

7. Li D, Li H, Liu H, Bao H, Zhu T, Tian J, Li H, Li J, Guo X, Zhuang Z, Cai G, Yang Y (2020) Impact of electroacupuncture stimulation on postoperative constipation for patients undergoing brain tumor surgery. J Neurosci Nurs 52(5):257-262 (in China)

8. Medic G, Wille M, Hemels ME (2017) Short- and long-term health consequences of sleep disruption. Nat Sci Sleep 9:151-161

9. Zhang X, Giovannucci EL, Wu K, Gao X, Hu F, Ogino S, Schernhammer ES, Fuchs CS, Redline S, Willett WC, Ma J (2013) Associations of self-reported sleep duration and snoring with colorectal cancer risk in men and women. Sleep 36(5):681-688

10. Luo J, Sands M, Wactawski-Wende J, Song Y, Margolis KL (2013) Sleep disturbance and incidence of thyroid cancer in postmenopausal women the Women's Health Initiative. Am J Epidemiol 177(1):42-49

11. Fang HF, Miao NF, Chen CD, Sithole T, Chung MH (2015) Risk of cancer in patients with insomnia, parasomnia, and obstructive sleep apnea: a nationwide nested case-control study. J Cancer 6(11): $1140-1147$

12. Cheung V, Yuen VM, Wong GTC, Choi SW (2019) The effect of sleep deprivation and disruption on DNA damage and health of doctors. Anaesthesia 74:434-440

13. Collins KP, Geller DA, Antoni M, Donnell DM, Tsung A, Marsh JW, Burke L, Penedo F, Terhorst L, Kamarck TW, Greene A, Buysse DJ, Steel JL (2017) Sleep duration is associated with survival in advanced cancer patients. Sleep Med 32:208-212

14. Mo YL, Li L, Qin L, Zhu XD, Qu S, Liang X, Wei ZJ (2014) Cognitive function, mood, and sleep quality in patients treated with intensity-modulated radiation therapy for nasopharyngeal cancer: a prospective study. Psycho-oncology 23(10):1185-1191

15. Tian J, Chen GL, Zhang HR (2011) Sleep status of cervical cancer patients and predictors of poor sleep quality during adjuvant therapy. Support Care Cancer 23(5):1401-1408

16. Savard J, Ivers H, Villa J, Caplette-Gingras A, Morin CM (2011) Natural course of insomnia comorbid with cancer: an 18-month longitudinal study. J Clin Oncol 29(26):3580-3586

17. Morin CM, Bélanger L, LeBlanc M, Ivers H, Savard J, Espie CA, Mérette C, Baillargeon L, Grégoire JP (2009) The natural history of 
insomnia: a population-based 3-year longitudinal study. Arch Intern Med 169(5):447-453

18. Palesh O, Aldridge-Gerry A, Zeitzer JM, Koopman C, Neri E, Giese-Davis J, Jo B, Kraemer H, Nouriani B, Spiegel D (2014) Actigraphy-measured sleep disruption as a predictor of survival among women with advanced breast cancer. Sleep 37(5):837-842

19. Lockefeer JP, De VJ (2013) What is the relationship between trait anxiety and depressive symptoms, fatigue, and low sleep quality following breast cancer surgery? Psycho-oncology 22(5):1127-1133

20. Akman T, Yavuzsen T, Sevgen Z, Ellidokuz H, Yilmaz AU (2015) Evaluation of sleep disorders in cancer patients based on Pittsburgh Sleep Quality Index. Eur J Cancer Care 24(4):553-559

21. Phillips KM, Jim HS, Donovan KA, Pinder-Schenck MC, Jacobsen PB (2012) Characteristics and correlates of sleep disturbances in cancer patients. Support Care Cancer 20:357-365

22. Spielman AJ, Caruso LS, Glovinsky PB (1987) A behavioral perspective on insomnia treatment. Psychiatr Clin North Am 10(4):541-553

23. Perlis ML, Morales KH, Vargas I et al (2021) The natural history of insomnia: does sleep extension differentiate between those that do and do not develop chronic insomnia? J Sleep Res 14:e13342

24. Espie CA (2002) Insomnia: conceptual issues in the development, persistence, and treatment of sleep disorder in adults. Annu Rev Psychol 53:215-243

25. Dahiya S, Ahluwalia MS, Walia HK (2013) Sleep disturbances in cancer patients: underrecognized and undertreated. Cleve Clin J Med 80(11):722-732

26. Otte JL, Carpenter JS, Manchanda S, Rand KL, Skaar TC, Weaver M, Chernyak Y, Zhong X, Igega C, Landis C (2015) Systematic review of sleep disorders in cancer patients: can the prevalence of sleep disorders be ascertained? Cancer Med 4(2):183-200

27. Liu K, Chen XZ, Zhang YC et al (2020) The value of spleenpreserving lymphadenectomy in total gastrectomy for gastric and esophagogastric junctional adenocarcinomas: a long-term retrospective propensity score match study from a high-volume institution in China. Surgery S0039-6060(20):30526-30522

28. Wang X, Zhang WH, Chen CX et al (2018) Investigation and analysis of symptom group in postoperative patients with gastric cancer. Nurs Pract Res 15(14):8-10

29. Dodd MJ, Miaskowski C, Paul SM (2001) Symptom clusters and their effect on the functional status of patients with cancer. Oncol Nurs Forum 28(3):465-470

30. Molassiotis A, Wengström Y, Kearney N (2010) Symptom cluster patterns during the first year after diagnosis with cancer. J Pain Symptom Manag 39(5):847-858

31. Palesh OG, Roscoe JA, Mustian KM, Roth T, Savard J, Ancoli-Israel S, Heckler C, Purnell JQ, Janelsins MC, Morrow GR (2010) Prevalence, demographics, and psychological associations of sleep disruption in patients with cancer: University of Rochester Cancer CenterCommunity Clinical Oncology Program. J Clin Oncol 28(2):292-298

32. Davidson JR, MacLean AW, Brundage MD, Schulze K (2002) Sleep disturbance in cancer patients. Soc Sci Med 54(9):1309-1321

33. Okuyama T, Akechi T, Kugaya A, Okamura H, Imoto S, Nakano T, Mikami I, Hosaka T, Uchitomi Y (2000) Factors correlated with fatigue in disease-free breast cancer patients: application of the Cancer Fatigue Scale. Support Care Cancer 8(3):215-222

34. Chen ML, Tseng HC (2006) Symptom clusters in cancer patients. Support Care Cancer 14(8):825-830

35. Ho SY, Rohan KJ, Parent J, Tager FA, McKinley PS (2015) A longitudinal study of depression, fatigue, and sleep disturbances as a symptom cluster in women with breast cancer. J Pain Symptom Manag 49(4):707-715
36. Amin MB, Edge SB, Greene FL et al (2016) AJCC cancer staging manual, 8th edn. Springer, New York, pp 203-220

37. Psychiatric Branch of Chinese Medical Association (2001) The Chinese Classification and the Diagnose Criterion of Mental Disorder (CCMD-3). Shandong Technology Press, Jinan, pp 9168 (in China)

38. Buysse DJ, Reynolds CF 3rd, Monk TH et al (1989) The Pittsburgh Sleep Quality Index: a new instrument for psychiatric practice and research. Psychiatry Res 28(2):193-213

39. So WKW, Dodgson J, Tai JWM (2003) Fatigue and quality of life among Chinese patients with hematologic malignancy after bone marrow transplantation. Cancer Nurs 26(3):211-219

40. Zigmond AS, Snaith RP (1983) The hospital anxiety and depression scale. Acta Psychiatr Scand 67(6):361-370

41. Sun ZX, Liu HX, Jiao LY et al (2017) Reliability and validity of hospital anxiety and depression scale. Chin J Clin (Electron Ed) 11(02):198-201 (in China)

42. Osman A, Barrios FX, Gutierrez PM, Kopper BA, Merrifield T, Grittmann L (2000) The pain catastrophizing scale: further psychometric evaluation with adult samples. J Behav Med 23(4):351-365

43. Morris BA, Thorndike FP, Ritterband LM, Glozier N, Dunn J, Chambers SK (2015) Sleep disturbance in cancer patients and caregivers who contact telephone-based help services. Support Care Cancer 23(4):1113-1120

44. Ohayon MM, Roth T (2001) What are the contributing factors for insomnia in the general population? J Psychosom Res 51(6):745-755

45. Pai A, Sivanandh B, Udupa K (2020) Quality of sleep in patients with cancer: a cross-sectional observational study. Indian J Palliat Care 26(1):9-12

46. Lewandowska A, Rudzki G, Lewandowski T et al (2020) Quality of life of cancer patients treated with chemotherapy. Int J Environ Res Public Health 17(19):E6938

47. Bagot JL, Marechaud N, Deana N, Wendling J (2018) Wendling J. Homeopathic treatment of insomnia and symptom clusters related to cerebral chemotoxicity in oncology. Homeopathy 107(4):292-298

48. Trudel-Fitzgerald C, Savard J, Ivers H (2013) Evolution of cancerrelated symptoms over an 18-month period. J Pain Symptom Manag 45(6):1007-1018

49. Alvaro PK, Roberts RM, Harris JK (2013) A systematic review assessing bidirectionality between sleep disturbances, anxiety, and depression. Sleep 36(7):1059-1068

50. Li P, Wang CM, Li F (2018) A relevant research between spontaneous activity of resting state of brain area and severity of illness of patients with EOD under functional magnetic resonance imaging. China Med Equip 15(6):61-66

51. Wang EF, Liu LY, Zhang HJ et al (2015) Evaluation of the resting state MRI brain default network in patients with primary insomnia accompanied by depressive symptoms. Chin J Neurol 48(11):1000-1006

52. Yang Y, Hu M, Ge HM (2016) Serum level of neuropeptide Y and substance $\mathrm{P}$ among depressive patients accompanied by insomnia. J Int Psychiatry 43(5):781-783 (in China)

53. $\mathrm{Xu} \mathrm{JN} \mathrm{(2016)} \mathrm{Analysis} \mathrm{of} \mathrm{the} \mathrm{clinical} \mathrm{characteristics} \mathrm{of} \mathrm{gastrointes-}$ tinal tumor cancer-induced fatigue and observation of the interventional effect of Yiqi Jianpi Bushen Fang. Beijing University of Chinese Medicine (in China)

54. Theobald DE (2004) Cancer pain, fatigue, distress, and insomnia in cancer patients. Clin Cornerstone 6(Suppl 1D):S15-S21

Publisher's note Springer Nature remains neutral with regard to jurisdictional claims in published maps and institutional affiliations. 